NASA/TM-1998-208497

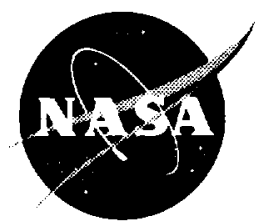

Probabilistic Modeling of High-Temperature Material Properties of a 5-Harness 0/90 Sylramic Fiber/CVI-SiC/MI-SiC Woven Composite

Vinod K. Nagpal

Modern Technologies Corporation, Middleburg Heights, Ohio

Michael Tong and P.L.N. Murthy

Lewis Research Center, Cleveland, Ohio

Subodh Mital

University of Toledo, Toledo, Ohio

National Aeronautics and

Space Administration

Lewis Research Center 
Available from

NASA Center for Aerospace Information 7121 Standard Drive

Hanover, MD 21076

Price Code: A03
National Technical Information Service 5285 Port Royal Road Springfield, VA 22100 Price Code: A03 


\title{
PROBABILISTIC MODELING OF HIGH-TEMPERATURE MATERIAL PROPERTIES OF A 5-HARNESS 0/90 SYLRAMIC FIBER/CVI-SIC/ MI-SIC WOVEN COMPOSITE
}

\author{
Vinod K. Nagpal and Michael Tong \\ Modern Technologies Corporation \\ Middleburg Heights. Ohio 44130 \\ P.L.N. Murthy \\ National Aeronautics and Space Administration \\ Lewis Research Center \\ Cleveland, Ohio 44135 \\ and \\ Subodh Mital \\ University of Toledo \\ Toledo, Ohio 43606
}

\section{SUMMARY}

An integrated probabilistic approach has been developed to assess composites for high temperature applications. This approach was used to determine thermal and mechanical properties and their probabilistic distributions of a 5-harness 0/90 Sylramic fiber/CVI-SiC/MI-SiC woven Ceramic Matrix Composite (CMC) at high temperatures. The purpose of developing this approach was to generate quantitative probabilistic inform-ation on this CMC to help complete the evaluation for its potential application for HSCT combustor liner. This approach quantified the influences of uncertainties inherent in constituent properties called primitive variables on selected key response variables of the $\mathrm{CMC}$ at $2200^{\circ} \mathrm{F}$. The quantitative information is presented in the form of Cumulative Density Functions (CDFs), Probability Density Functions (PDFs) and primitive variable sensitivities on response. Results indicate that the scatters in response variables were reduced by 30 to 50 percent when the uncertainties in the primitive variables, which showed the most influence, were reduced by 50 percent.

\section{INTRODUCTION}

The Enabling Propulsion Material (EPM) Project team of NASA Lewis Research Center is evaluating the Sylramic fiber/CVI-SiC/MI-SiC 0/90 5-harness woven composite for its potential applications for combustors liner in the High Speed Civil Transport (HSCT). This study was initiated to generate quantitative inform-ation needed to characterize the behavior of this composite. This information was considered to be an essential part of the evaluation process.

The $0 / 90$ woven composite is constructed with two sets of mutually orthogonal sets of fiber tows inter-laced with each other, to form a layer. The layer is then coated with BN by means of chemical vapor infiltration (CVI). The CVI process is also used to deposit $\mathrm{SiC}$ into the fiber tow (CVI-SiC). This CVI-SiC matrix fills up the fiber tow area and generally forms a thin coating around the fiber tow. Melt-infiltrated process is then used to deposit the $\mathrm{SiC}$ hetween the fiber tows(MI-SiC). A typical section of a 5-harness (every 5th tow is woven) composite is shown in figure 1.

Propulsion System components in the HSCT are required to have an assured life of several thousand hours. The process of reliability estimations for these components is quite complex and requires a knowledge of uncertainties that occur in various scales and at various stages. Unlike conventional materials, the pro-perties of the CMC display considerable scatter because of the uncertainties involved at two levels. The two levels are (1) the constituent level (fiber, matrix, and interphase) properties and (2) the fabrication level. The uncertainties at these two levels cause scatter at the laminate level. The laminate level includes fiber volume fraction, interphase thickness and properties, matrix void volume fraction and geometrical parameters of the laminate-such as fiber tow spacing and the fiber count per tow. 
It is necessary to quantify scatter in the selected key response variables by taking into account the inherent uncertainties in the variables at levels (1) and (2), also called primitive variables, in order to be able to assure the required reliability of structural components.

Fabrication related variables consist of boron nitride (BN) coating thickness, fiber tow spacing, fiber and void volume fractions. Material variables consist of moduli, thermal conductivities, and thermal expansion coefficients of Sylramic fiber. CVI-SiC and MI-SiC matrices, and BN coating. The selected key response variables are those that characterize the composite behavior such as the in-plane modulus, through-thickness thermal expansion coefficient and thermal conductivity.

In the current practice of deterministic approaches, uncertainties are usually accounted for by the safety factors. This could often result in a design with unquantifiable risk of failure. Not knowing the risk of failure quantitatively may raise major obstacles in the application of CMCs for aerospace components.

\section{OBJECTIVES}

The primary objective of this work is to characterize the selected CMC when there are uncertainties in the constituent properties and fabrication related variables. The response characterization consist of predicting the mean values their standard deviations and probability distributions. Such in formation is extremely valuable for selection of a material because it provides a way to determine the risk of failure. Also this information is essential in developing a cost effective service/maintenance schedule.

The specific objectives of the current study are to:

1. Estimate the composite properties and their probabilistic distributions of a 5-harness 0/90 Sylramic fiber/CVI-SiC/MI-SiC woven ceramic matrix composite (CMC), accounting for the uncertainties in its constituent properties and fabrication related variables.

2. Quantify the influence of uncertainties in the material ard fabrication related variables on the overall thermal and mechanical properties of the CMC and identify the most influential ones

3. Quantify the scatter in the key response variables when the tolerances are tightened on the most influential primitive variables

Variable of the Study

Primitive Variables. - These include constituent property variablı:s and fabrication related variables. The constituent property variables include fiber Young's Modulus, thermal conductivity, and coefficient of thermal expansion of fiber, Young's Modulus thermal conductivity and coeffizient of thermal expansion of matrix, Young's Modulus, thermal conductivity and coefficient of thermal expansion of interface. The fabric-ation related variables are interface thickness. fiber tow spacing, fiber volume fraction, and void volume fraction.

Response.-These are in-plane modulus, through thickness thermal expansion coefficient and thermal conductivity of laminate.

\section{Analysis Approach}

The approach used in this study was to combine ceramic matrix composite analysis figure 2 , embedded in the computer code CEMCAN (Ceramic Matrix Composite Analyzer) (rets. 1 to 2) and fast probability integration techniques (FPI) available in NESSUS (Numerical Evaluation of Stochastic Structures Under Stress) (ref. 3). A schematic of the integrated approach is shown in figure 3.

Fast Probability Integrator (FPI), which is a part of NESSUS code, was used to perform probabilistic analysis utilizing the properties generated by CEMCAN. In addition. FPI was ased to perform sensitivity analysis to rank primitive variables in order of magnitude of their influence on a specific response variable.

The primitive variables are assumed to be independent and have normal distributions. For most engineering problems, variables have generally been seen to have normal distributions. In some cases vari-ables have lognormal and Weibull distributions. These distributions are not significantly different form the assumed distribution. 
The primitive variables are perturbed within their assumed distributions. Response variables are estimated for each set of values of primitive variables. Based on all the values thus generated, distributions of the response variables are generated.

FPI is also used to generate Probability Density Functions (PDF) and Cumulative Density Functions (CDF) for ply/laminate properties of the CMC. A PDF gives a relationship between a range of values of a property (response variable) and the probability of its occurrence. $A C D F$ gives a relationship between a value up to certain magnitude of a property and the probability of its occurrence. In addition, the response variable sensitivities to inherent scatter in primitive variables are obtained from FPI.

\section{Simulation Technique and Stepwise Procedure}

There are a number of approaches available for obtaining probabilistic response for a given set of independent primitive variables. One approach which is commonly used is called Monte-Carlo simulation technique. While this approach provides almost exact solutions, it is fairly expensive and time consuming approach.

In the Monte Carlo technique, random values of the input variables are selected from their distributions. These input values are used to compute the values of the response variables deterministically. This process of selecting random input values and calculating corresponding response values is called a com-putational run here onwards. Generally, it requires tens of thousands of computational runs to build reasonably accurate probabilistic density distributions of response variables.

To minimize the number of computational runs to develop PDFs without sacrificing accuracy, NASA Lewis took initiative to develop a Probabilistic Structural Analysis Method (PSAM). PSAM includes a code called Fast Probability Integrator (FPI). FPI approximates Monte Carlo Technique fairly accurately to develop PDFs and requires several orders of magnitude less number of computational runs. This code was developed to solve a large class of engineering problems.

A 4 step procedure to characterize the behavior of the selected CMC using integrated approach is as follows:

1. Selected the key response variable(s) and corresponding primitive variables and their probabilistic distributions.

2. Ran CEMCAN for the selected set of values (means \& standard deviations) of primitive variables to get material properties using the micro-macro-mechanics.

3. Used FPI to generate a table of laminate property (key response variables) values that correspond to perturbed values of the primitive variables.

4. Ran FPI making use of the previously generated table to compute the CDF and the corresponding sensitivities of the response and rank the primitive variables in the order of their influences.

Sensitivity values could be + or - in nature. A positive value indicates that particular primitive variable has a direct effect on the response variable and negative value indicates an inverse effect. Variable with the highest absolute sensitivity value is defined to be the most influential variable. Variable with next lower absolute sensitivity value is second most influential variable and so on. This defines the order of influence of the variables.

The sensitivity information thus obtained from FPI is very useful from the design point of view. For example, reliability in design can be improved when uncertainties in the most influential variables are reduced. Those primitive variables which do not have significant influences deterministically could never-theless have strong influences on the response scatter if these primitive variables have large uncertainties. Weak physical variables with large uncertainties may have probabilistic sensitivity factors more important than strong physical variables with small standard deviations. Variables with no scatter (deterministic) will obviously result in zero values for the sensitivity implying that the scatter in the key response variables is unaffected by such variables.

\section{RESULTS AND DISCUSSIONS}

Mean values and standard deviations of the primitive variables are shown in table I. Mean values in this table have been obtained from a NASA report (ref. 5) Standard Deviations of the means have been estimated based on years of experience of professional's in this field. As mentioned before, scatters in composite properties have been 
observed at various levels both due to inherent uncertainties in the $m$ tterial properties and fabrication processes. Uncertainties may be present at the constituent (fiber, matrix or inter phase) level and at the ply level (fiber volume ratio, void volume ratio, thickness of interfacial region etc.)

The mean values and standard deviations obtained for the selected key response variables using the information given in table I and this study approach, are listed in table II. Also listed in this table are the values of the same response variables obtained experimentally. These values have been provided by NASA Lewis personnel. The predicted values and experimentally obtained values have remarkable agreements.

The scatter in the key response variables in this study refers to - and + three standard deviations from the mean value. This range was particularly selected because this is the standard used by the designers particularly in the Aerospace Industry to design components for over 99 percent survival rate.

Constituent properties include fiber modulus, matrix modulus, coaling modulus, thickness of the BN coating, coefficients of the thermal expansion of the fiber, matrix and the interphase, thermal conductivities of the fiber. Fabrication related variables include coating thickness, fiber tow spacing, fiber volume fraction and void volume fraction.

In-plane and through-the-thickness Young's Modulus, and coefficient of thermal expansion and thermal conductivity are selected to be the key response variables. In-plane and through-the-thickness Young's Modulus are selected to characterize the CMC's mechanical behavior. and coefficients of thermal expansion and thermal conductivity to characterize thermal behavior.

The probability and cumulative density functions of in-plane Young's Modulus, along with its sensitivity to the various primitive variables are shown in figures 4 to 6 . Relative frequency in figure 4 means how often a given value of a variable will be obtained when a very large number of tests are conducted. The computed mean value of in-plane modulus for the selected CMC is $33.33 \mathrm{Msi}$; with a 3 sigma scatter range of 29.54 to $37.13 \mathrm{Msi}$.

As expected, the three most influential variables for in-plane Young's Modulus are fiber and CVI-SiC moduli, and fiber tow spacing (fig. 6). In controlling the scatter in the in-plane modulus, an outstanding pay-off will result from controlling the scatter in the fiber and CVI-SiC moduli, and fiber tow spacing. Other primitive variables such as modulus of the $\mathrm{BN}$ coating and void volume fraction have negligible influence.

These results imply that tightening the tolerances of CVI-SiC moduli and fiber tow spacing will result in lower scatter in the CMC in-plane modulus. Tightening tolerances in the remaining primitive variables will result in a zero to marginal reduction in the scatter. To estimate the reduction in the scatter, the PDF of the modulus was regenerated with the uncertainties of the three most influential variables, i.e., fiber/CVI-SiC/MI-SiC moduli, reduced by 50 percent. It shows that the scatter range of the in-plane modulus is reduced by 29 percent. The results are shown in figure 7 .

The CDFs, PDFs were developed (not shown from here onwards) and sensitivity analysis was performed on through-the-thickness Young's Modulus. The sensitivity analysis show that all the primitive variables considered. with the exception of fiber and BN moduli, and void volume fraction, significantly influence (with sensitivity factor more than 0.3) the scatter in through-the-thickness Young's Modulus figure 8. By reducing uncertainties of the top three most influential variables (fiber volume fraction. BN thickness. and fiber tow spacing) by 50 percent, the scatter in the through-the-thickness ply modulus is reduced by 35 peicent, figure 9 .

Sensitivity analyses results for in-plane and through-the-thickne $s$ thermal conductivities are shown in figures 10 and 11 , respectively. The predicted scatter for the in-plane thermal conductivity is 8.82 to $12.29 \mathrm{Btu} / \mathrm{hr}-\mathrm{ft}-{ }^{\circ} \mathrm{F}$ and for through-the-thickness is 7.16 to $10.49 \mathrm{Btu} \mathrm{hr}-\mathrm{ft}-{ }^{\circ} \mathrm{F}$. Fiber thermal conductivity is the most influential variable for in-plane composite thermal conductivity whils the BN coating thermal conductiv-ity is the most influential for through-the-thickness thermal conductivity. Alsc, two other primitive variables, CVI-SiC and MI-SiC conductivities significantly influence the in-plane conductivity.

In case of through-the-thickness thermal conductivity, there are 3 additional variables which have significant influence. They are BN thickness, fiber conductivity and CVI-SiC conductivity. Fiber tow thermal conductivity (i.e., fiber and CVI-SiC conductivities) has the most influence on the scatter of the in-plane thermal conductivity. Void volume fraction has negligible influence on both the in-plane a id through-the-thickness thermal conductivities.

By reducing the uncertainties in the top three influential variables by 50 percent. the scatter range of the in-plane and through-the-thickness ply thermal conductivities are recuced by 38 and 29 percent, respectively. They are shown in figures 12 and 13 . 
Sensitivity analyses for in-plane and through-the-thickness coefficients of thermal expansion are shown in figures 14 and 15 . The predicted mean values of in-plane and through-the-thickness coefficients of thermal expansion are essentially the same 3.37 and $3.29 \mathrm{ppm} /{ }^{\circ} \mathrm{F}$, respectively. The scatter ranges for both in-plane and thru-thickness expansion coefficients are also quite similar 2.78 to 3.97 and 2.66 to $3.92 \mathrm{ppm} /{ }^{\circ} \mathrm{F}$, respectively.

For the in-plane thermal expansion coefficient, there are 3 variables that have significant influence. They, in their order of influence, are coefficients of thermal expansion of fiber, CVI-SiC and MI-SiC. In the case of through-the-thickness expansion coefficient, there are only 2 variables that have significant influence. They also in the order of their significance, are coefficients of thermal expansion of CVI-SiC and MI-SiC. The remaining variables essentially have insignificant influences. This behavior is expected as the in-plane thermal expansion of composite is essentially controlled by the fiber tows. These results are to some extent intuitively obvious. The behavior in the through-the-thickness direction is essentially matrix dominated and therefore the matrix properties have greater effect on the response scatter.

By reducing the standard deviations of the three most influential variables by 50 percent, the scatter range of the in-plane and through-the-thickness ply thermal expansion coefficients are reduced by 50 and 49 percent, respectively. They are shown in figures 16 and 17 .

\section{SUMMARY}

An integrated probabilistic approach has been developed and used to determine thermal and mechanical properties and their probabilistic distributions for the CMC which is a prime candidate for HSCT combustor liner application.

Influences of uncertainties inherent in primitive variables on the key response variables of the CMC at $2200^{\circ} \mathrm{F}$ were quantified. Primitive variables included material and fabrication related variables. Material variables are moduli, thermal conductivities and thermal expansion coefficients of Sylramic fiber, CVI-SiC and MI-SiC matrices and BN coating. Fabrication related variables are BN coating thickness, fiber tow spacing, fiber and void volume fractions.

Cumulative density and probability density functions have been developed for all the key response variables which include Young's Modulus, coefficient of thermal expansion and thermal conductivites. Also, sensitivity analyses were performed to identify the primitive variables which have the most influence on the response variables. This information is directly useful for the designers.

The results indicate that the scatter in the key response variables were reduced by 30 to 50 percent when the uncertainties in the most influential primitive variables were reduced by 50 percent.

For EPM community, the results are most useful for material development efforts. The approach developed in this study could help define where to expand efforts/resources to optimize key material response variables and help to better interpret the measured data.

\section{FUTURE WORK}

This study has provided a good approach to the selected CMC characterization and provided very useful results. In order to get the maximum value out of this study, we strongly recommend that this study to be continued to complete the following three items. These three items are (1) quantify scatters of available life prediction models incorporating uncertainties in their primitive variables, (2) incorporate manufacturers input for cost and feasibility of controlling the primitive variables and (3) quantify the influences and significance of the remaining primitive variables on the selected key response variables and other key response variables which have not been included before. 


\section{APPENDIX}

\section{CERAMIC MATRIX COMPOSITE MICROMECHANICS AND MACROMECHANICS}

CEMCAN utilizes a novel and unique fiber substructuring technique in conjunction with the conventional micromechanics hased on the mechanics of materials approach. Reference 1 describes the usage of the code and the various equations embedded in CEMCAN with theoretical aspects are described in reference 2.

Due to the unique fiber substructuring technique, it offers several advantages over conventional unit cell based micromechanics theories. It allows for a more accurate micromechanical representation of interfacial conditions and provides much greater detail in local stresses.

CEMCAN's methodology consists of incremental synthesis of the properties starting from the constituents-namely the fiber, matrix and the interphase to form a slice. The slice level properties are obtained using composite micromechanics equations which are represented by simplified closed form equations. The slice level properties are in general equivalent elastic properties such as moduli Poisson's ratios, thermal expansion coefficients and heat conductivities.

From slice to a single lamina and subsequently to the laminate level, the code utilizes repeated applications of classical laminate theory to obtain composite level properties/response. Given a specific set of loads, the code can progressively decompose, as indicated in the figure 2, retracing the steps followed during the upward synthesis to yield laminate, ply, and slice level responses and constituent microstresses.

The code can predict ply and laminate level thermal and mechanical properties as well as detailed description of resulting microstresses due to an applied load. It also accounts for nonlinear effects due to material nonlinearities as well as due to the local stress redistribution resulting from progressive fracture. One can account for fabrication related parameters in analyzing the response of ceramic matrix composites. The detailed description of this methodology is documented in reference 4. 


\section{REFERENCES}

1. Mital, S.K., Murthy, P.L.N.: CEMCAN-Ceramic Matrix Composites Analyzer User's Guide-Version 2.0, NASA TM-107187, April 1996.

2. Mital, S.K., Murthy, P.L.N. and Chamis, C.C.: Micromechanics for Ceramic Matrix Composites via Fiber Substructuring, Journal of Composite Materials, Vol. 29, No. 5, 1995, pp. 614-633.

3. Wu, Y.-T.: Computational Methods for Efficient Structural Reliability and Reliability Sensitivity Analysis, AIAA Journal, Vol. 32, No. 8, Aug. 1994, pp. 1717-1723. Also presented at the 34th SDM Conference, 1993.

4. Murthy, P.L.N., Chamis, C.C., and Mital, S.K.: Computational Simulation of Continuous Fiber-Reinforced Ceramic Matrix Composites Behavior. NASA TP-3602, 1996.

5. Mital, S.K., Tong, M., Murthy P.L.N. and DiCarlo, J.A.: "Micromechanics-Based Modeling of Thermal and Mechanical Properties of an Advanced SiC/SiC Composite Material," NASA TM-97-206295, Dec. 1997.

TABLE I.-PRIMITIVE INPUT VARIABLES DISTRIBUTION PARAMETERS

\begin{tabular}{|l|c|c|c|}
\hline \multicolumn{1}{|c|}{ Variable } & $\begin{array}{c}\text { Mean } \\
\text { value }\end{array}$ & $\begin{array}{c}\text { Standard } \\
\text { deviation }\end{array}$ & Distribution \\
\hline Young's modulus. (Msi) & 52 & \pm 2.6 & Normal \\
Sylramic fiber & 58 & \pm 2.9 & \\
CVI-SiC & 47 & \pm 2.4 & \\
MI-SiC & 10 & \pm 0.5 & \\
BN & & & \\
Thermal conductors (Btu/ft-hr- ${ }^{\circ}$ F) & 11.8 & \pm 1.2 & \\
Sylramic fiber & 15.6 & \pm 1.6 & \\
CVI-SiC & 16.9 & \pm 1.7 & \\
MI-SiC & 2.0 & \pm 0.2 & \\
BN & & & \\
Coefficient of thermal exponent (ppn ${ }^{\circ}$ F) & 6.0 & \pm 0.60 & \\
Sylramic fiber & 6.0 & \pm 0.60 & \\
CVI-SiC & 6.2 & \pm 0.62 & \\
MI-SiC & 3.7 & \pm 0.37 & \\
BN & 10 & \pm 1 & \\
BN thickness (percent within tow) & 22 & \pm 1 & \\
Fiber tow spacing (ends/in.) & 42 & \pm 2 & \\
Fiber volume fraction (percent overall) & \\
Void volume fraction (percent within tow) & 9 & \pm 1 & \\
\hline
\end{tabular}

"Assume volume fraction of MI-SiC matrix stays constant at 13 percent. Fiber and void volume fraction varies at the expense of CVI-SiC.

TABLE II. - RESULTS

\begin{tabular}{|l|c|c|c|c|}
\hline \multirow{2}{*}{} & \multicolumn{2}{|c|}{ Prediction } & \multicolumn{2}{|c|}{ Test data } \\
\cline { 2 - 5 } & Mean & Scatter range & Mean & Scatler range \\
\hline Young's modulus (Msi) & 33.33 & 29.54 to 37.13 & 32.13 & 28.00 to 33.20 \\
In plane & 19.30 & 15.68 to 22.92 & not available & not available \\
Thru-thickness & & & & \\
& & & & \\
Thermal condition (Btu/hr-ft- ${ }^{\circ} \mathrm{F}$ ) & 10.71 & 8.82 to 12.59 & 10.30 & not available \\
In-plane & 8.82 & 7.16 to 10.49 & 8.60 & not available \\
Thru thickness & & & & \\
Coefficient of thermal exponent & & & & \\
(ppm/ ${ }^{\circ} \mathrm{F}$ ) & & & & \\
In-plane & & & \\
Thru-thickness & 3.37 & 2.78 to 3.97 & 2.60 & not available \\
not available
\end{tabular}




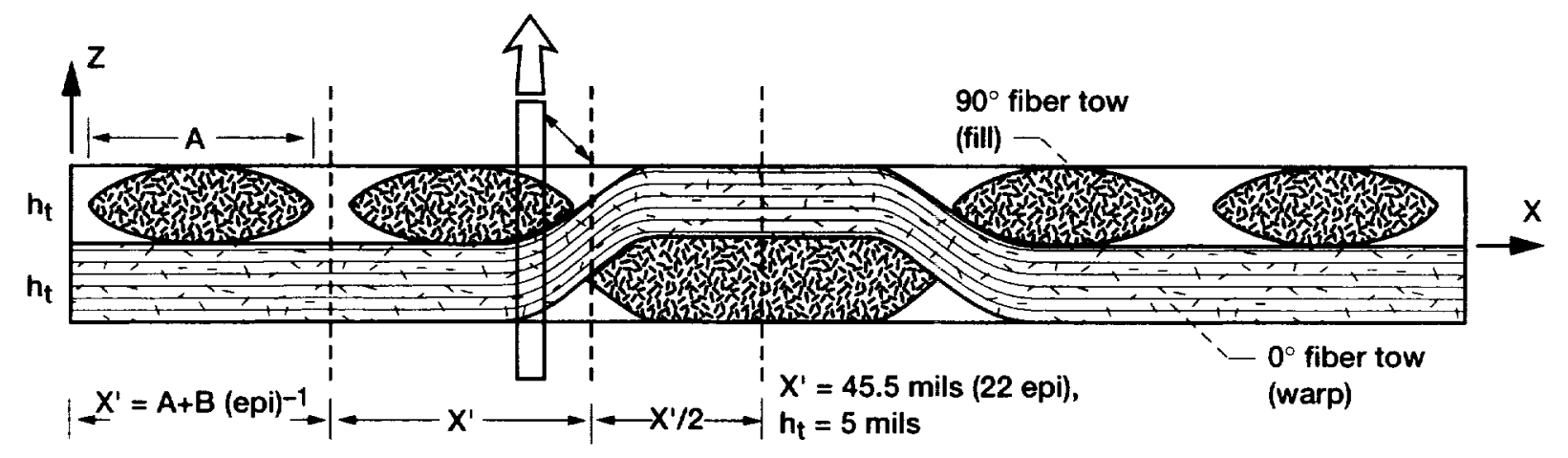

Figure 1.-"Telescoping scales" for analysis of woven architectures. 5 Harness satin weave architecture.

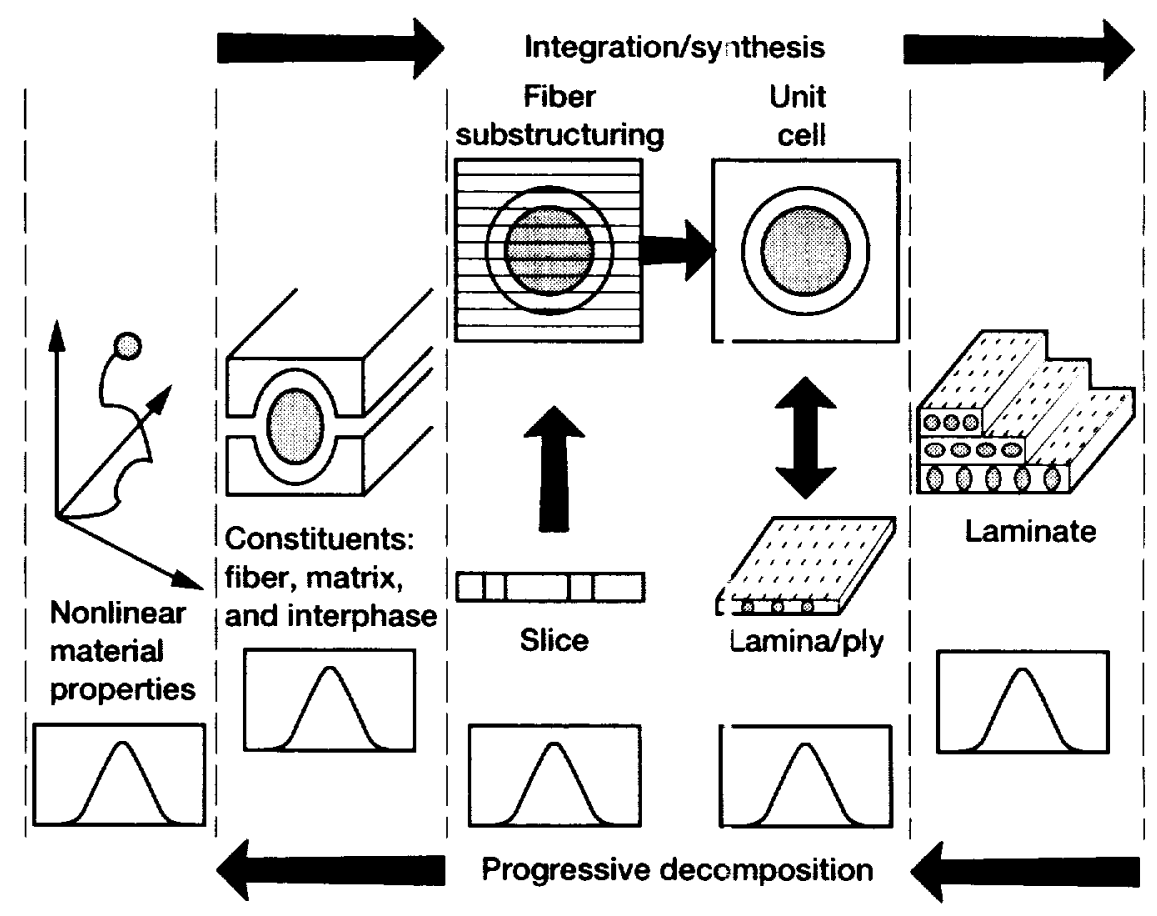

Figure 2.-Integrated probabilistic ceramic matrix composite mechanics approach. 


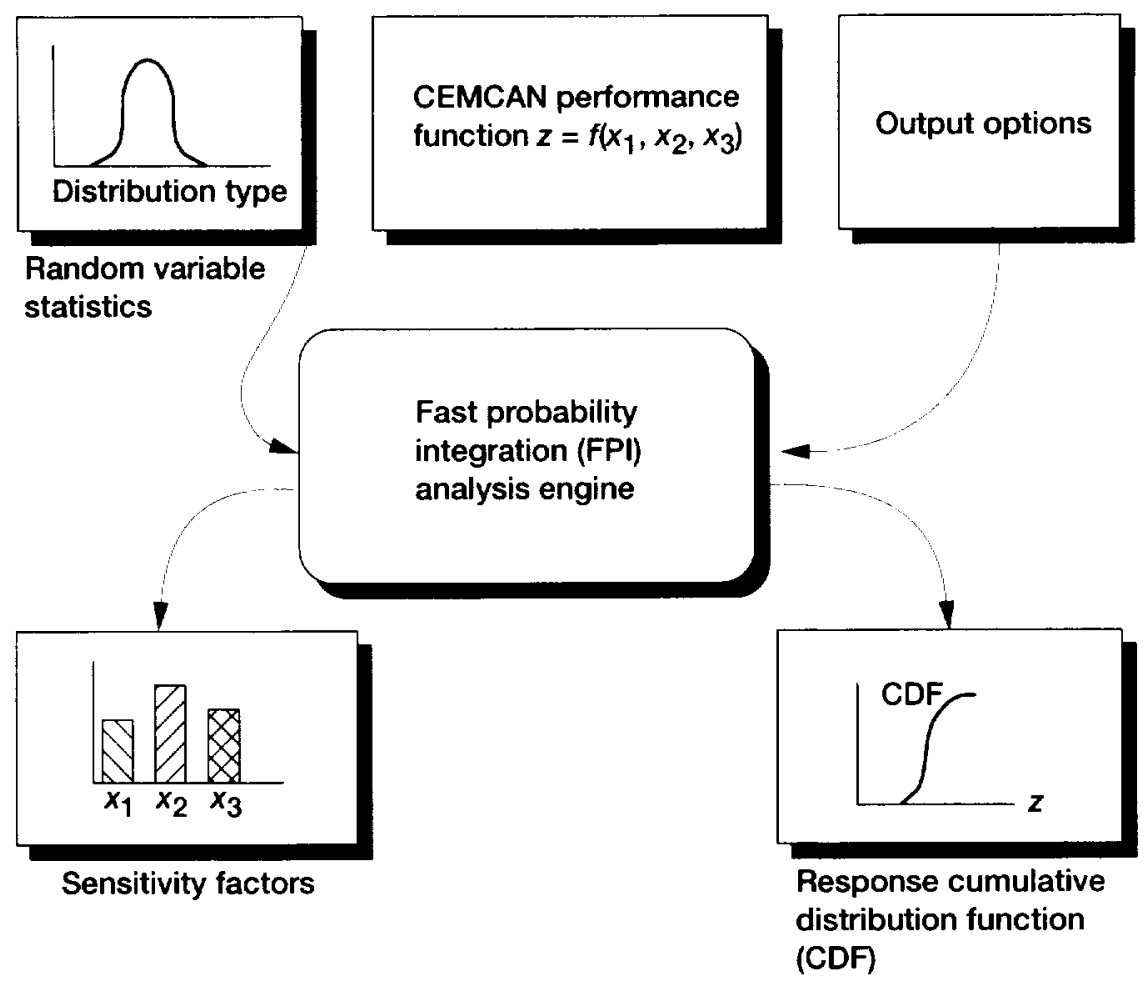

Figure 3.-Fast probability integration input-output schematic.

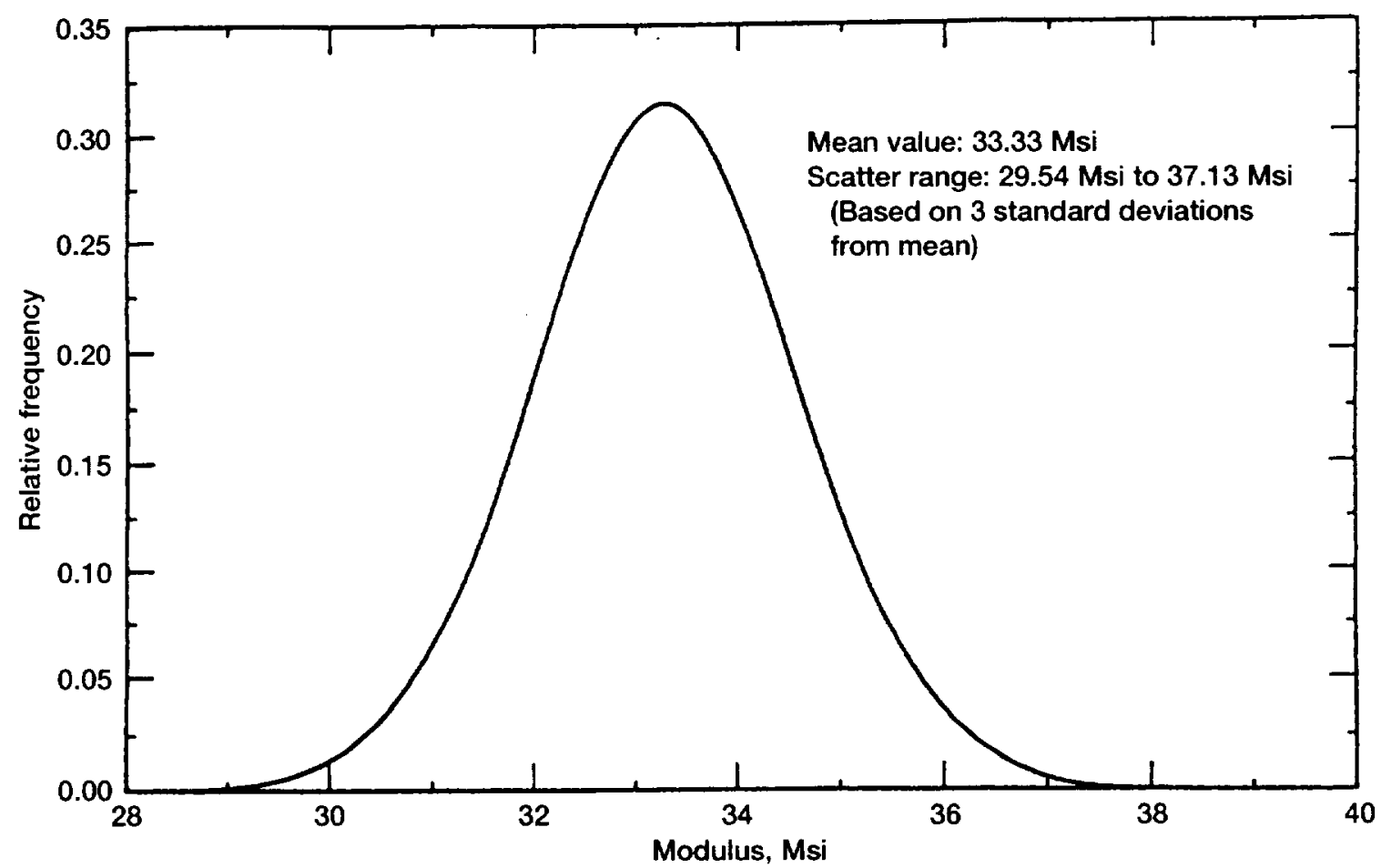

Figure 4.-PDF of in-plane Young's modulus. $0 / 90$ sylramic fiber/CVI-SiC/MI-SiC woven composite at $2200^{\circ} \mathrm{F}$. 


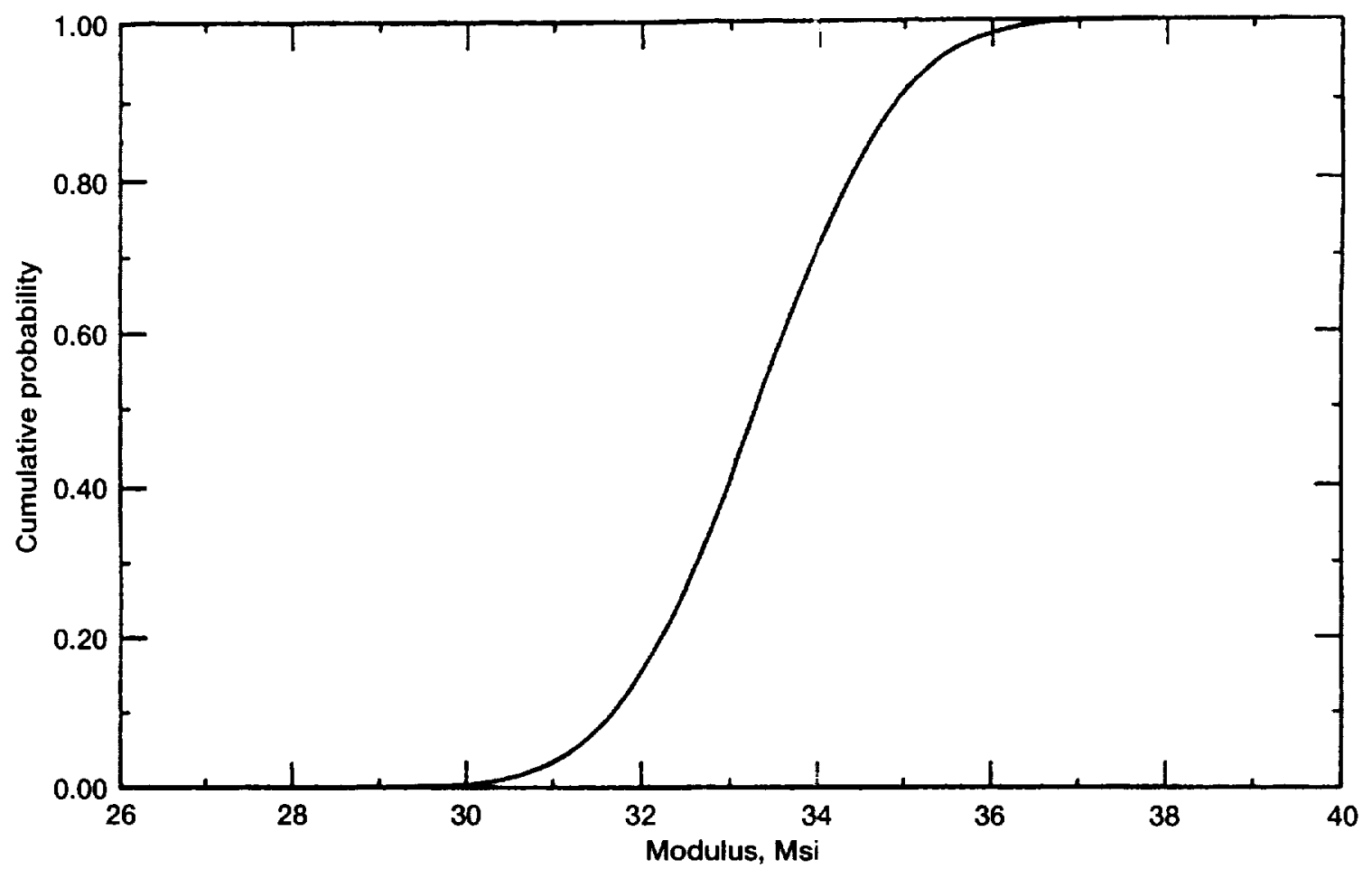

Figure 5. - CDF of in-plane Young's modulus. $0 / 90$ sylramic fiber/CVI-SiC/MI-SiC woven composite with $10 \% \mathrm{BN}$.

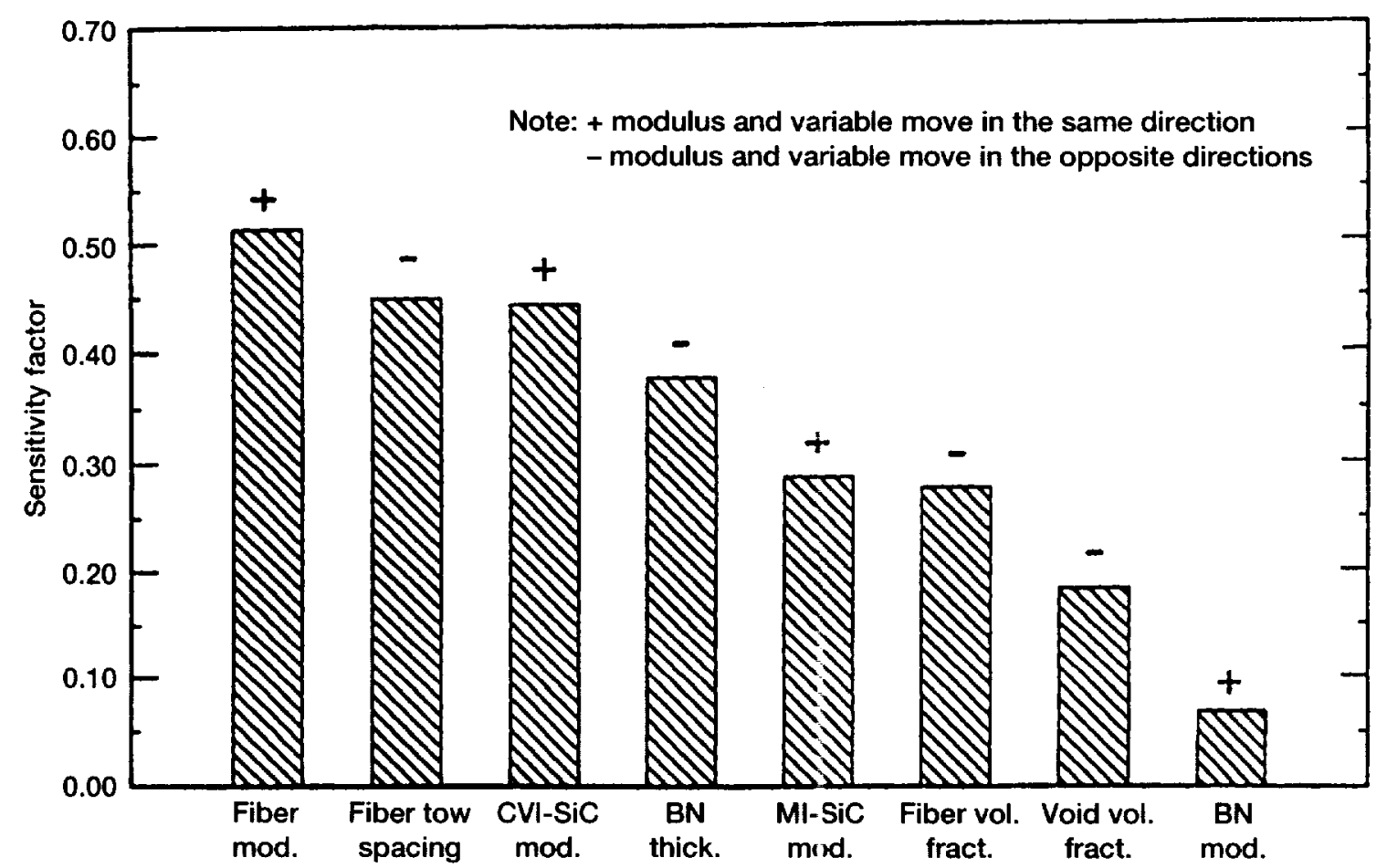

Figure 6.-Sensitivity of in-plane Young's modulus. $0 / 90$ sy:ramic fiber/CVI-SiC/MI-SiC woven composite at $2200^{\circ} \mathrm{F}$. 


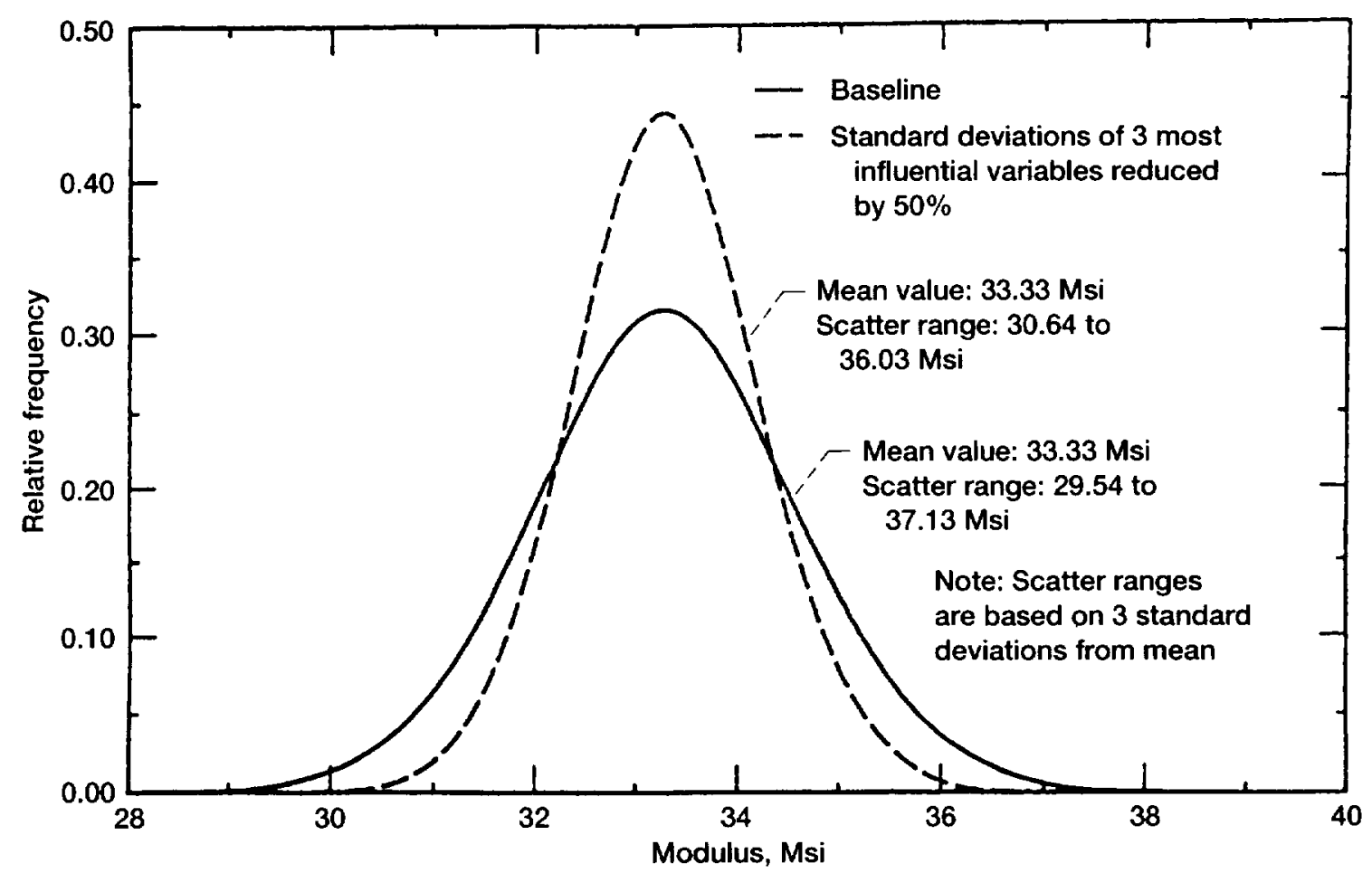

Figure 7.-PDF of in-plane Young's modulus. 0/90 sylramic fiber/CVI-SiC/MI-SiC woven composite at $2200^{\circ} \mathrm{F}$.

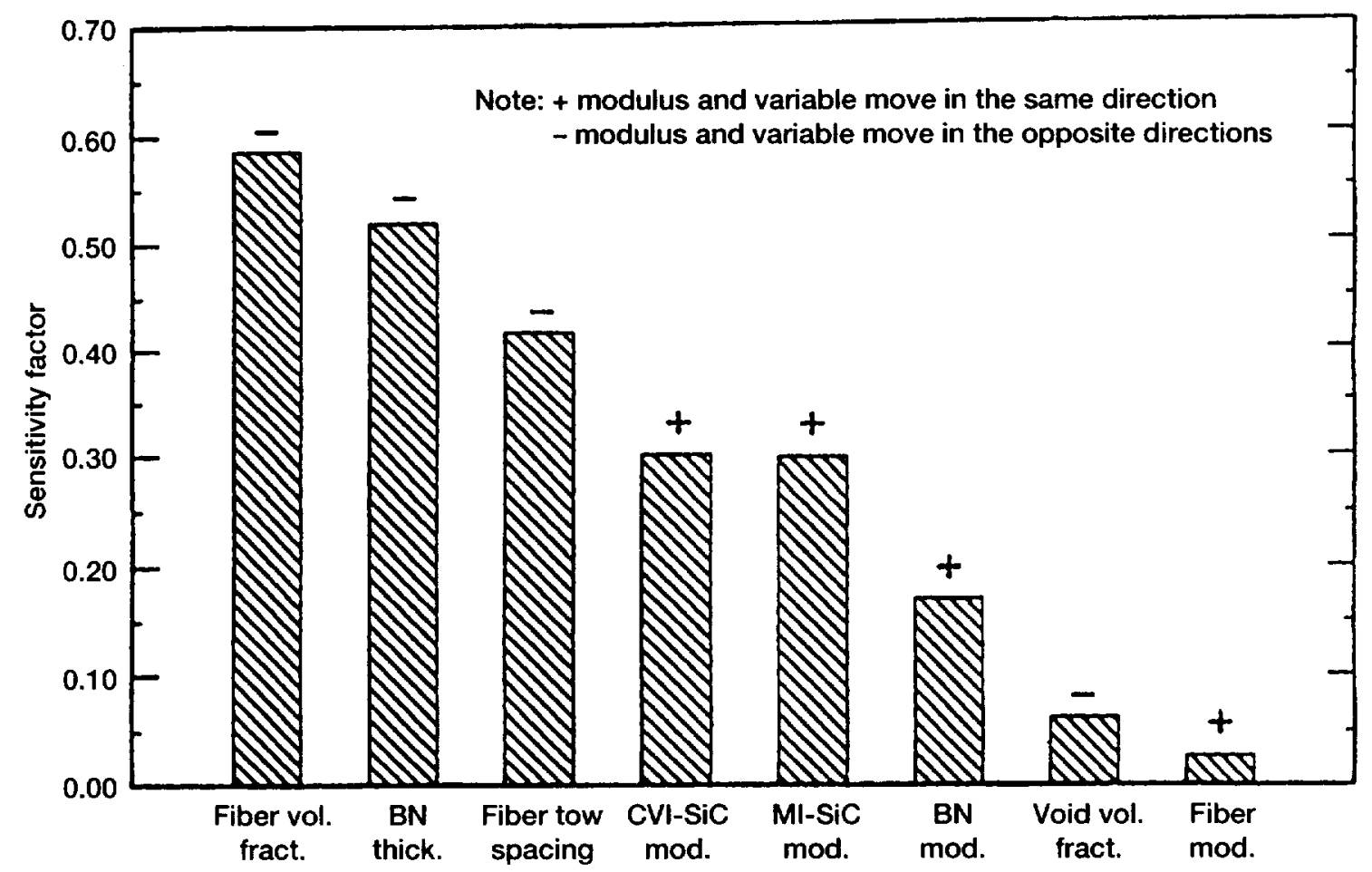

Figure 8.-Sensitivity of thru-thickness Young's modulus. 0/90 sylramic fiber/CVI-SiC/MI-SiC woven composite at $2200^{\circ} \mathrm{F}$. 


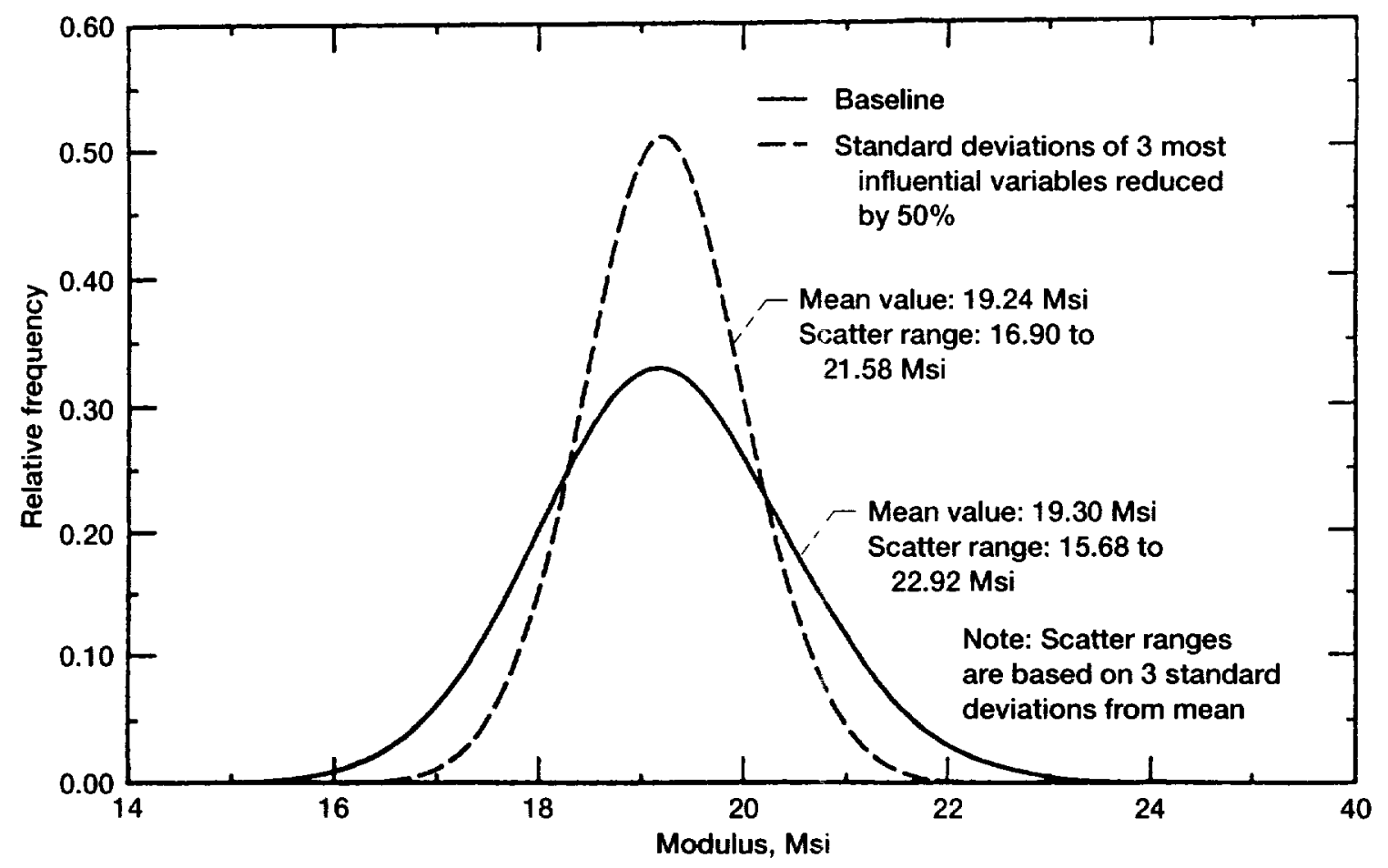

Figure 9.-PDF of thru-thickness Young's modulus. $0 / 90$ sylramic fiber/CVI-SiC/MI-SiC woven composite at $2200^{\circ} \mathrm{F}$.

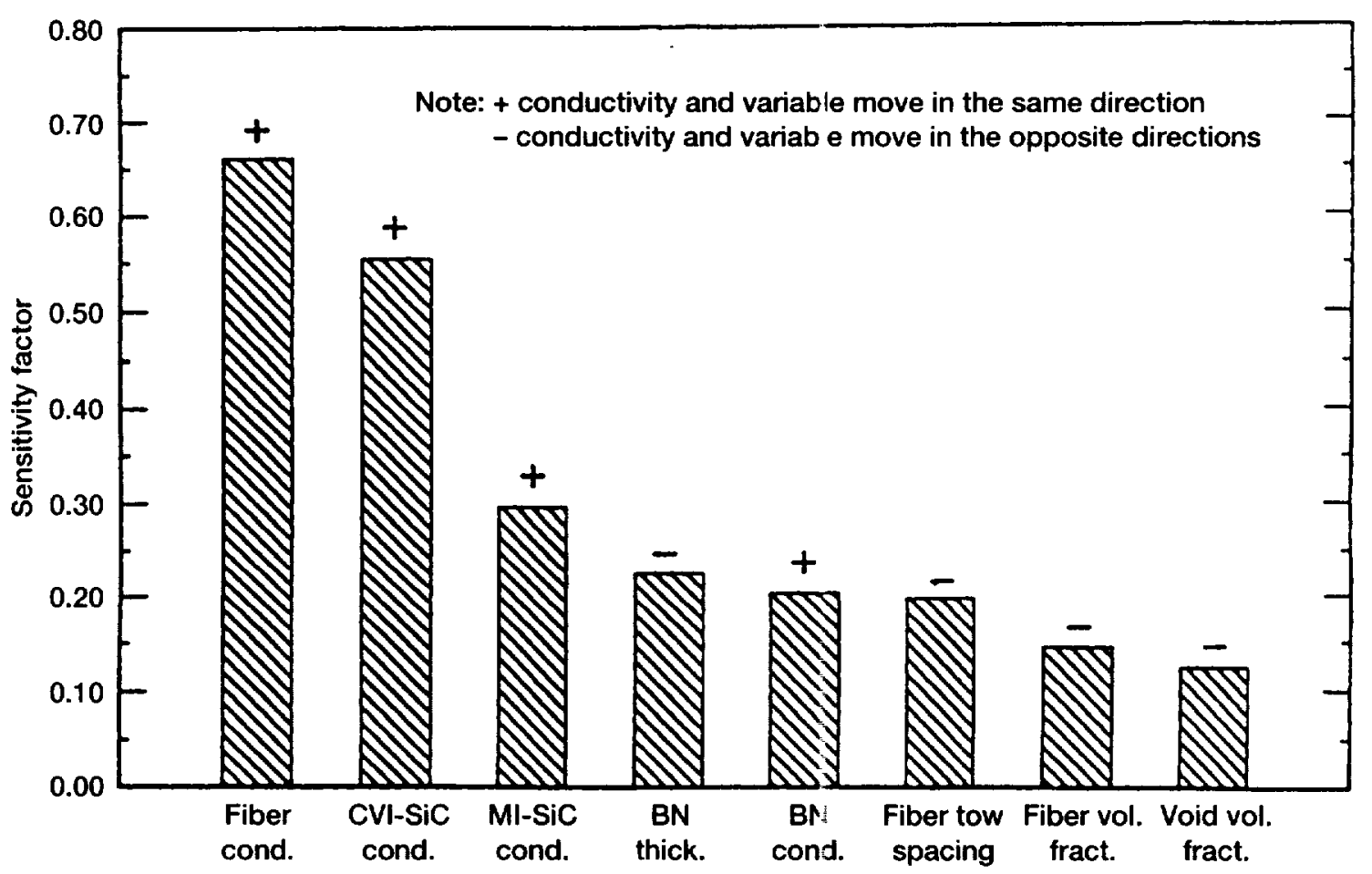

Figure 10.-Sensitivity of in-plane thermal conductivity. 0/90 sylramic fiber/CVI-SiC/MI-SiC woven composite at $2200^{\circ} \mathrm{F}$. 


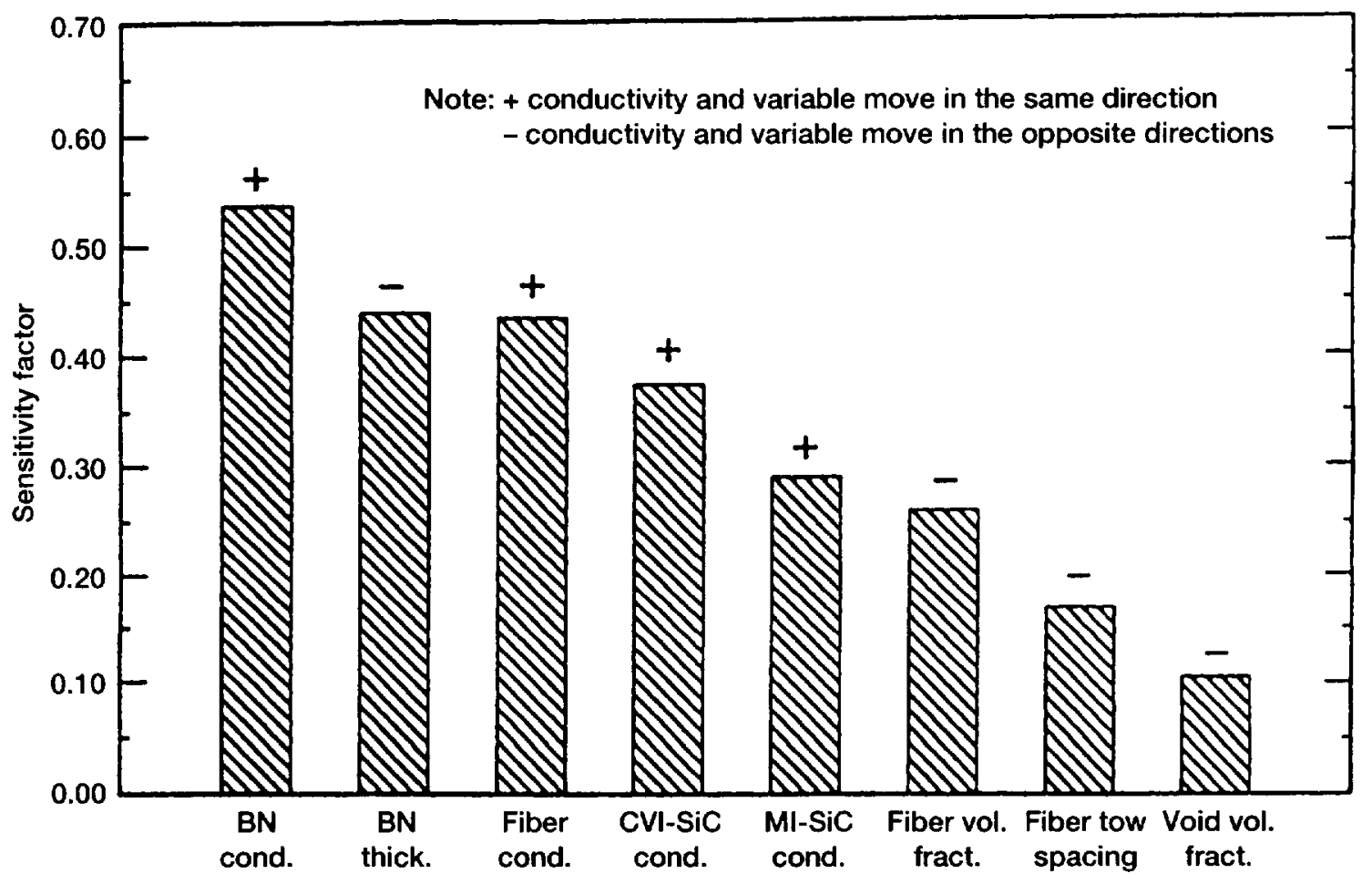

Figure 11.-Sensitivity of thru-thickness thermal conductivity. $0 / 90$ sylramic fiber/CVI-SiC/MI-SiC woven composite at $2200^{\circ} \mathrm{F}$.

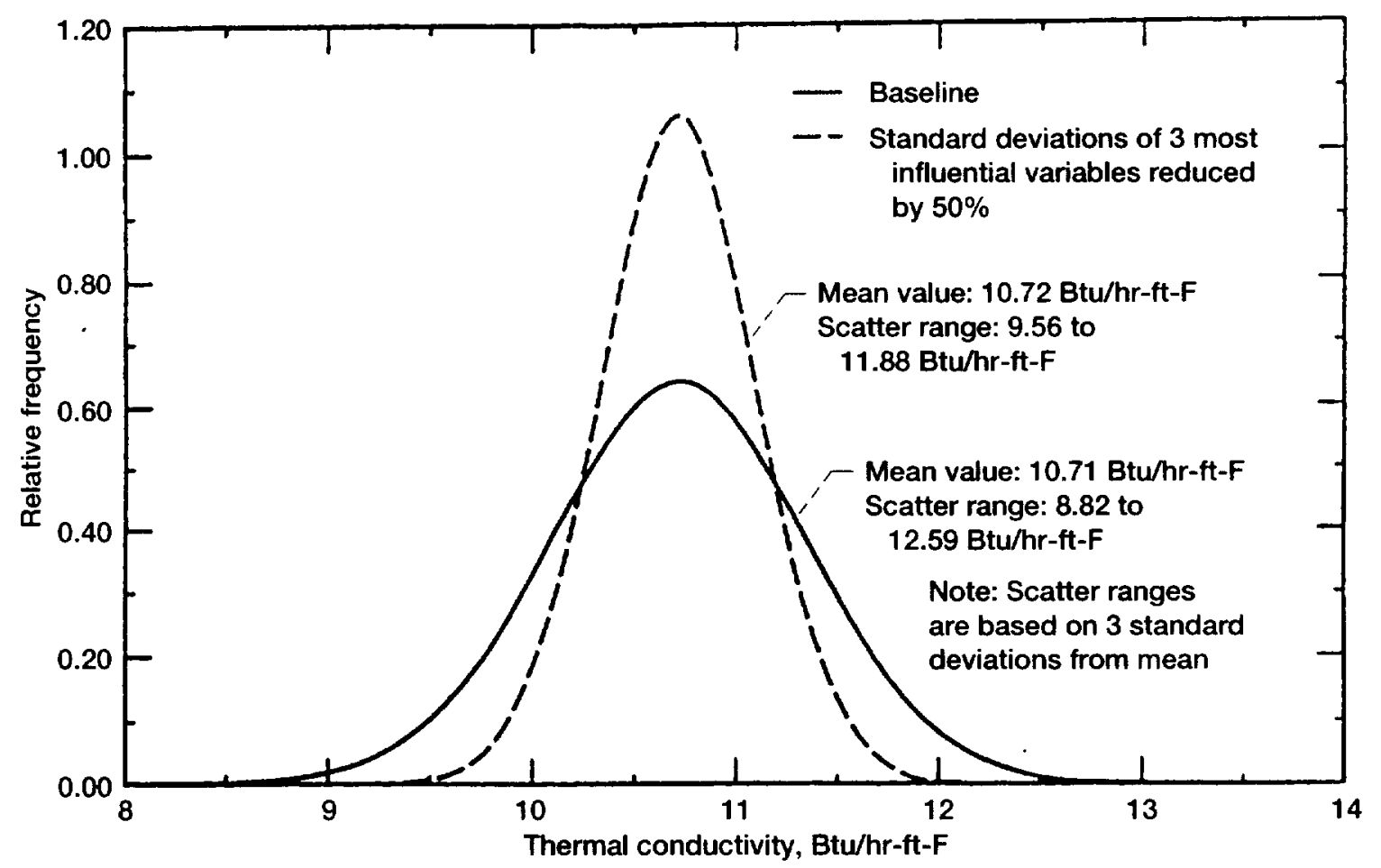

Figure 12.-PDF of in-plane thermal conductivity. $0 / 90$ sylramic fiber/CVI-SiC/MI-SiC woven composite at $2200^{\circ} \mathrm{F}$. 


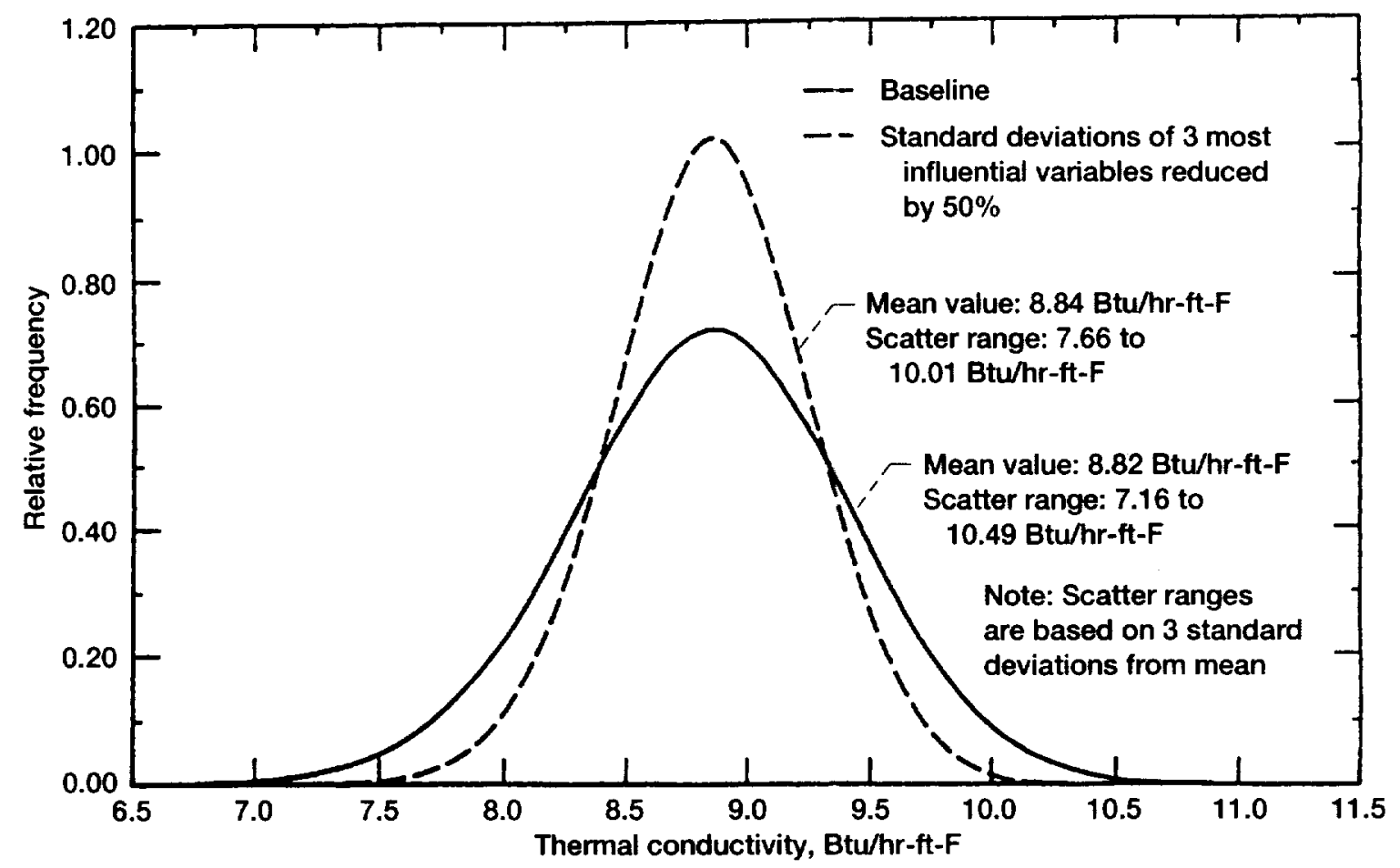

Figure 13.-PDF of thru-thickness thermal conductivity. $0 / 90$ sylramic fiber/CVI-SiC/MI-SiC woven composite at $2200^{\circ} \mathrm{F}$.

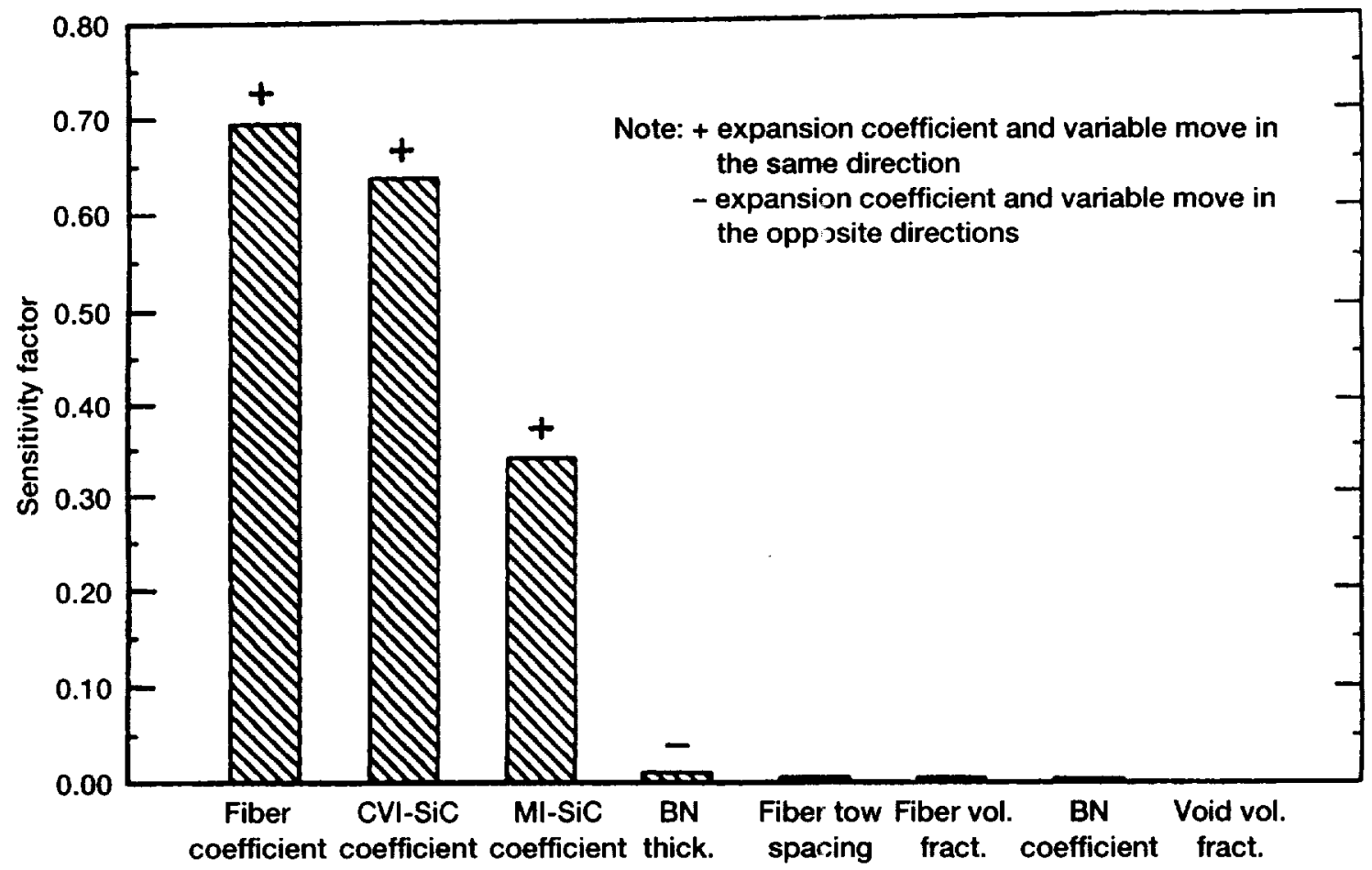

Figure 14.-Sensitivity of in-plane thermal expansion coeffic:ient. $0 / 90$ sylramic fiber/CVI-SiC/MI-SiC woven composite at $2200^{\circ} \mathrm{F}$. 


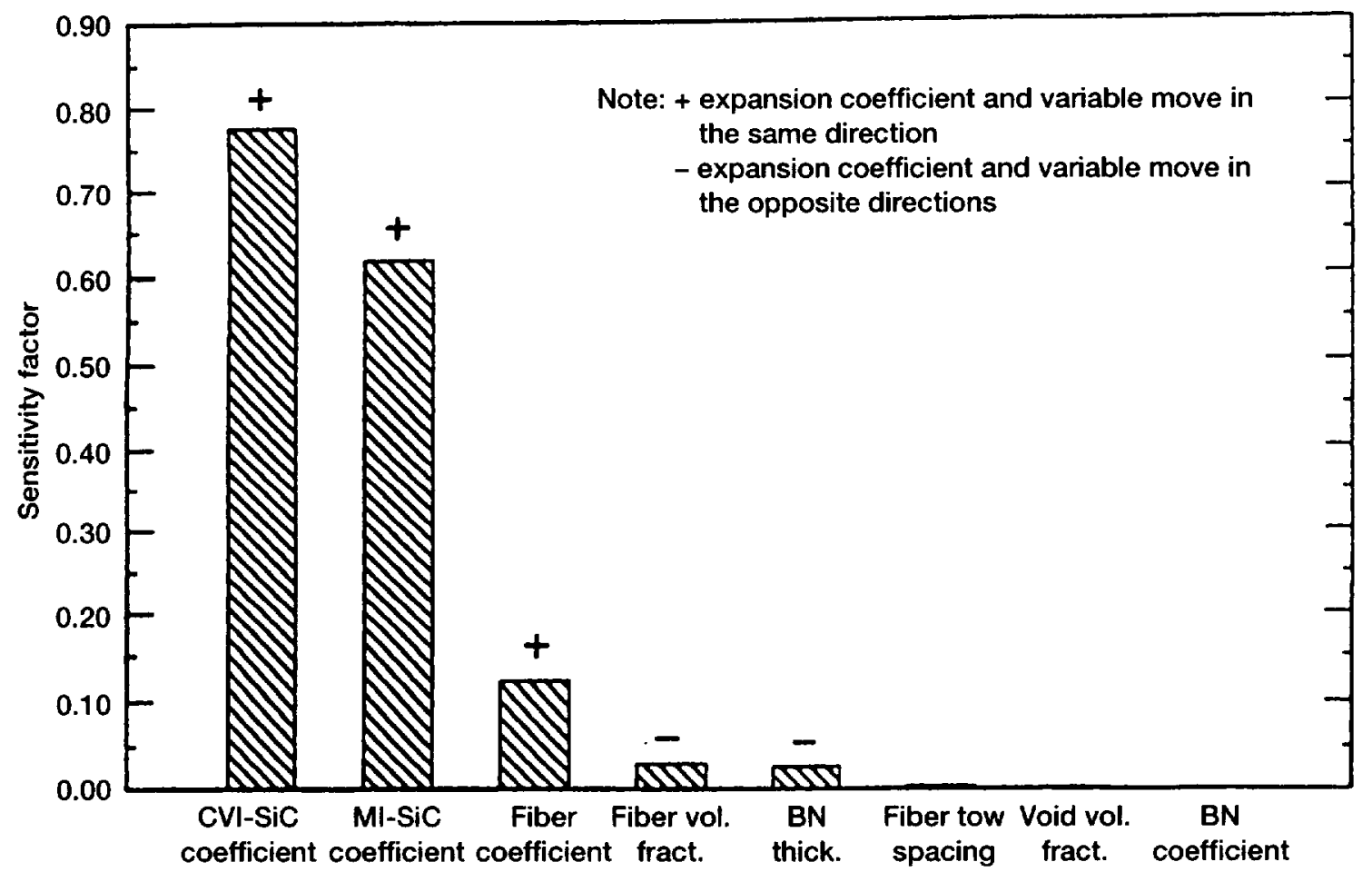

Figure 15.-Sensitivity of thru-thickness thermal expansion coefficient. 0/90 sylramic fiber/CVI-SiC/ MI-SiC woven composite at $2200^{\circ} \mathrm{F}$.

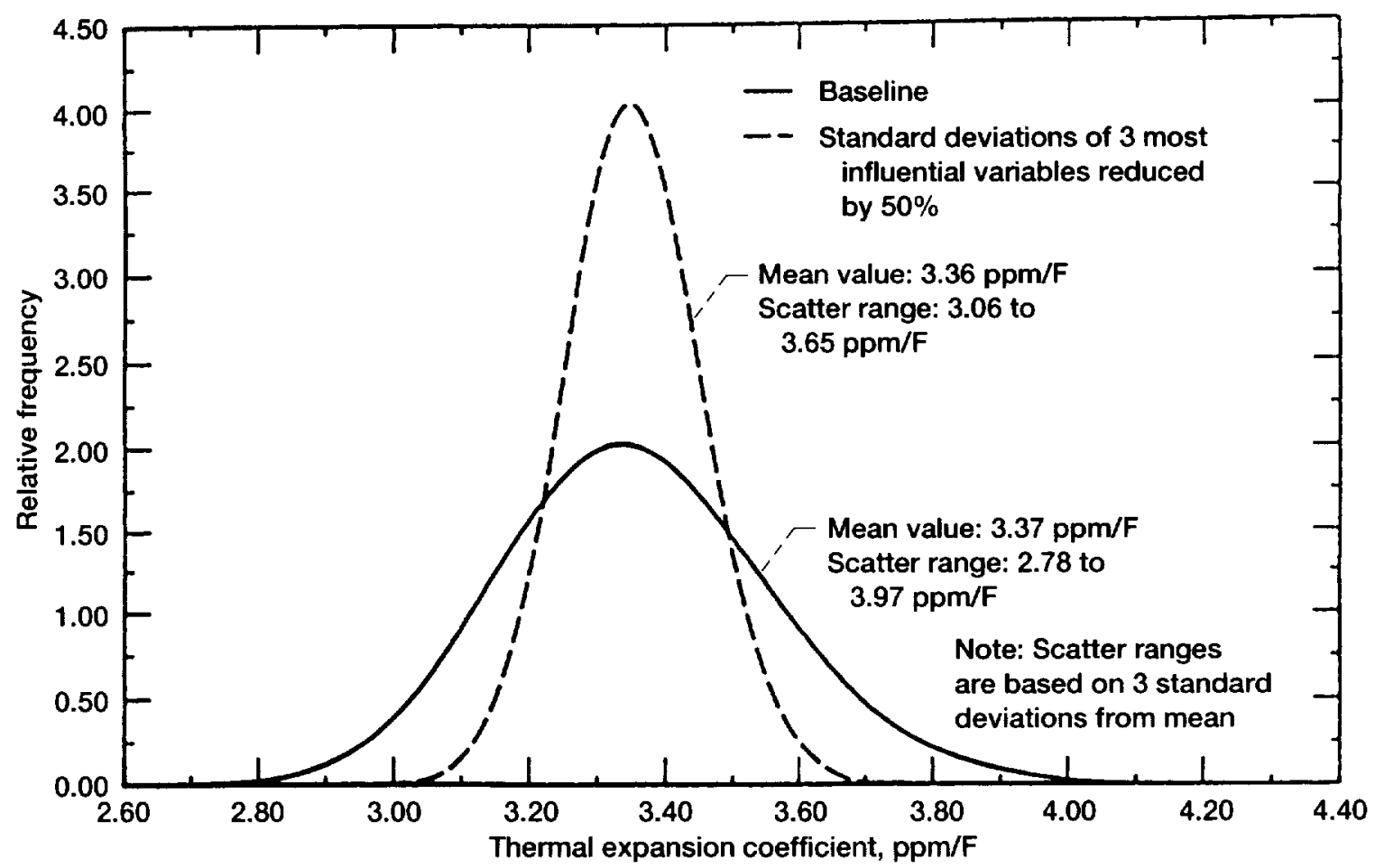

Figure 16.-PDF of in-plane thermal expansion coefficient. 0/90 sylramic fiber/CVI-SiC/MI-SiC woven composite at $2200^{\circ} \mathrm{F}$. 


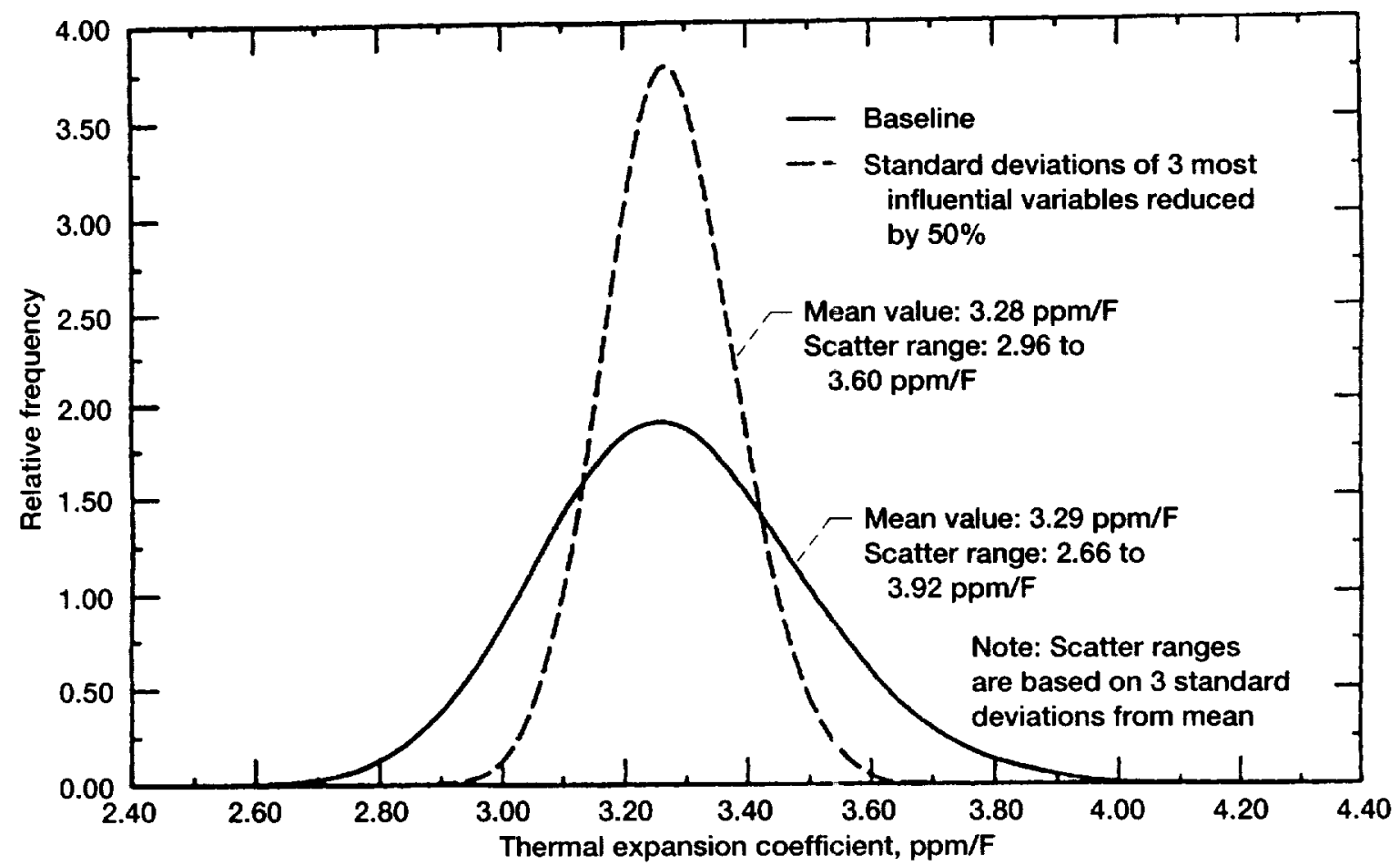

Figure 17.-PDF of thru-thickness thermal expansion coefficient. $0 / 90$ sylramic fiber/CVI-SiC/MI-SiC woven composite at $2200{ }^{\circ} \mathrm{F}$. 


\begin{tabular}{|c|c|c|c|c|}
\hline \multicolumn{3}{|c|}{ REPORT DOCUMENTATION PAGE } & \multicolumn{2}{|r|}{$\begin{array}{l}\text { Form Approved } \\
\text { OMB No. 0704-0188 }\end{array}$} \\
\hline \multicolumn{5}{|c|}{ 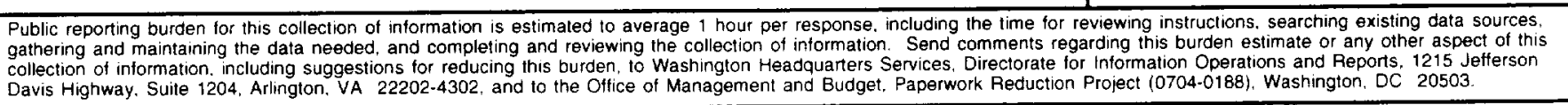 } \\
\hline 1. AGENCY USE ONLY (Leave blank) & $\begin{array}{r}\text { 2. REPOAT DATE } \\
\text { October } 1998\end{array}$ & \multicolumn{3}{|c|}{$\begin{array}{l}\text { 3. REPORT TYPE AND DATES COVERED } \\
\text { Technical Memorandum }\end{array}$} \\
\hline \multicolumn{3}{|c|}{$\begin{array}{l}\text { 4. TITLE AND SUBTITLE } \\
\text { Probabilistic Modeling of High-Temperature Material Properties of a 5-Harness } \\
\text { 0/90 Sylramic Fiber/CVI-SiC/MI-SiCWovenComposite }\end{array}$} & \multicolumn{2}{|c|}{ 5. FUNDING NUMBERS } \\
\hline \multicolumn{3}{|c|}{$\begin{array}{l}\text { 6. AUTHOR(S) } \\
\text { Vinod K. Nagpal, Michael Tong. P.L.N. Murthy, and Subodh Mital }\end{array}$} & \multicolumn{2}{|c|}{ WU $-537-(04-22-00$} \\
\hline \multicolumn{3}{|c|}{$\begin{array}{l}\text { National Aeronautics and Space Administration } \\
\text { Lewis Research Center } \\
\text { Cleveland, Ohio } 441.35-3191\end{array}$} & \multicolumn{2}{|c|}{$\begin{array}{l}\text { REPORT NUMBER } \\
\text { E-11292 }\end{array}$} \\
\hline \multicolumn{3}{|c|}{$\begin{array}{l}\text { 9. SPONSORING/MONITORING AGENCY NAME(S) AND ADDRESS(ES) } \\
\text { National Aeronautics and Space Administration } \\
\text { Washington, DC } 20546-0001\end{array}$} & \multicolumn{2}{|c|}{$\begin{array}{l}\text { 10. SPONSORING/MONITORING } \\
\text { AGENCY REPORT NUMBER } \\
\text { NASA TM-1998-208497 }\end{array}$} \\
\hline \multicolumn{5}{|l|}{ 11. SUPPLEMENTARY NOTES } \\
\hline \multicolumn{5}{|c|}{$\begin{array}{l}\text { Vinod K. Nagpal, Modern Technologies, Corporation, } 7530 \text { Lucerne Drive., Suite } 206 \text {, Middleburg Heights, Ohio } 44130 \text {; } \\
\text { Michael Tong and P.L.N. Murthy, NASA Lewis Research Center; Subodh Mital, University of Toledo. Toledo, Ohio. } \\
\text { Responsible person, Michael Tong, organization code } 2400,(216) 433-6739 .\end{array}$} \\
\hline \multirow{2}{*}{\multicolumn{3}{|c|}{$\begin{array}{l}\text { 12a. DISTRIBUTION/AVAILABILITY STATEMENT } \\
\text { Unclassified - Unlimited } \\
\text { Subject Category: } 24 \\
\text { This publication is available from the NASA Center for AeroSpace Intormation. (301) 621-0390. }\end{array}$}} & \multirow{2}{*}{\multicolumn{2}{|c|}{ 12b. DISTRIBUTION CODE }} \\
\hline & & & & \\
\hline \multicolumn{5}{|l|}{ 13. ABSTRACT (Maximum 200 words) } \\
\hline \multicolumn{5}{|c|}{$\begin{array}{l}\text { An integrated probabilistic approach has been developed to assess composites for high temperature applications. This } \\
\text { approach was used to determine thermal and mechanical properties and their probabilistic distributions of a } 5 \text {-harness } \\
0 / 90 \text { Sylramic fiber/CVI-SiC/MI-SiC woven Ceramic Matrix Composite (CMC) at high temperatures. The purpose of } \\
\text { developing this approach was to generate quantitative probabilistic information on this CMC to help complete the } \\
\text { evaluation for its potential application for HSCT combustor liner. This approach quantified the influences of uncertain- } \\
\text { ties inherent in constituent properties called primitive variables on selected key response variables of the CMC at } \\
2200^{\circ} \mathrm{F} \text {. The quantitative information is presented in the form of Cumulative Density Functions (CDFs). Probability } \\
\text { Density Functions (PDFs) and primitive variable sensitivities on response. Results indicate that the scatters in response } \\
\text { variables were reduced by } 30-50 \% \text { when the uncertainties in the primitive variables, which showed the most influence. } \\
\text { were reduced by } 50 \% \text {. }\end{array}$} \\
\hline \multirow{2}{*}{\multicolumn{3}{|c|}{$\begin{array}{l}\text { 14. SUBJECT TERMS } \\
\text { Ceramic matrix composite; Melt-infiltrated: Chemical vapor infiltration; } \\
\text { Thermal conducting }\end{array}$}} & & $\begin{array}{l}\text { 15. NUMBER OF PAGES } \\
22\end{array}$ \\
\hline & & & & $\begin{array}{r}\text { 16. PRICE CODE } \\
\mathrm{A} 03\end{array}$ \\
\hline $\begin{array}{l}\text { 17. SECURITY CLASSIFICATION } \\
\text { OF REPORT }\end{array}$ & $\begin{array}{l}\text { 18. SECURITY CLASSIFICATION } \\
\text { OF THIS PAGE }\end{array}$ & $\begin{array}{l}\text { 19. SECURITY CLASSIFICA } \\
\text { OF ABSTRACT }\end{array}$ & ATION & 20. LIMITATION OF ABSTRACT \\
\hline Unclassified & Unclassified & Unclassified & & \\
\hline
\end{tabular}


